\section{Combined injuries}

Studies have shown that teeth which sustain a combination of injuries are likely to experience a greater frequency of pulp necrosis and infection. ${ }^{1}$

\section{Pulp canal obliteration}

Teeth that have open apices, which are subject to extrusion, intrusion and lateral luxation, are at highest risk for pulp canal obliteration occurring. It may also commonly occur following root fractures. ${ }^{4}$

\section{Final considerations}

Traumatic dental injuries are not only distressing for the child and parent but also challenging for the dental team managing them. The final considerations are as follows:
- A structured approach should be undertaken, including robust documentation and intraoral/extraoral clinical photographs of patients recorded where possible. The literature shows that the use of a structured approach can significantly improve the quality of trauma records

- A careful and systematic approach to diagnosis should be undertaken

- The clinician should be alert to concomitant injuries involving the head and neck region and seek medical assistance if necessary

- For children, appropriate advice should be provided to parents on the best ways to manage acute symptoms and education on the potential long-term outcomes as a consequence of the dental injuries. Such advice should also be provided to adults who have sustained dental trauma

- Consideration should be given to a child's maturity, compliance and level of dental anxiety when discussing potential treatment visitation to prevent the potential of posttraumatic stress disorder and anxiety.

Conflict of interest

The authors declare no conflicts of interest.

\section{References}

1. Levin L, Day P, Hicks L et al. International Association of Dental Traumatology guidelines for the management of traumatic dental injuries: General introduction. Dent Traumatol 2020; 36: 309-313.

2. Andersson L, Andreasen J, Day P et al. International Association of Dental Traumatology guidelines for the management of traumatic dental injuries: 2. Avulsion of permanent teeth. Dent Traumatol 2012: 28: 88-96.

3. Day P, Flores $\mathrm{M}, \mathrm{O}^{\prime}$ Connell $\mathrm{A}$ et al. International Association of Dental Traumatology guidelines for the management of traumatic dental injuries: 3 . Injuries in the primary dentition. Dent Traumatol 2020; 36: 343-359.

4. Bourguignon C, Cohenca N, Lauridsen E et al. International Association of Dental Traumatology guidelines for the management of traumatic dental injuries: 1. Fractures and luxations. Dent Traumatol 2020; 36: 314-330.

\title{
Correction to: Book review: Odell's clinical problem solving in dentistry
}

The original article can be found online at https://doi.org/10.1038/s41415-021-2961-8

Correction note:

Book review article Br Dent J 2021; 230: 506.

When this article was initially published the editor's name was listed incorrectly as Edward Odell. The editors were: 'Avijit Banerjee \& Selvam Thavaraj'.

The journal apologises for any inconvenience caused. 